\title{
Spontaneous Chest Wall Hematoma - Unusual Presentation of Chronic Myeloid Leukemia
}

PETER GEORGE, ${ }^{1}$ SHISHIR NAGESH DUBLE, ${ }^{2}$ NARASIMHA HEGDE ${ }^{3}$

\begin{abstract}
:
Chronic Myeloid Leukemia (CML) is known for the variety of its clinical presentations. We report on a 45 year old male, who presented with sudden swelling over chest wall on lifting weight; and clinically with pallor and massive splenomegaly. The peripheral, bone marrow smears; and chromosomal study confirmed CML. In this report, we have depicted interesting clinical, sonographic and microscopic images. To our knowledge, this is possibly the first report on CML presenting as spontaneous chest wall hematoma.
\end{abstract}

Keyword: Spontaneous hematoma, chest wall hematoma, chronic myeloid leukemia.CML.

\section{Introduction:}

CML is the commonest haematological malignancy encountered in clinical practice; and known for its variability in presentation ${ }^{1}$. Spontaneous hematomas are not a usual presenting symptom of $\mathrm{CML}^{2,3,4}$. We noted a few reports of CML presenting with intra muscular and neuro-hematomas in the review of literature. We report, spontaneous chest wall hematoma as an uncommon presenting symptom of CML.

\section{Case Report:}

A 45 year old male, presented to the emergency department, with complaint of sudden swelling over the left chest wall (infra axillary area) on lifting a heavy object. The swelling was painfull and boggy to feel (figure-1). There was history of trauma redness around the area prior to its formation. On examination, he was pale, the vital signs were normal. The swelling was warm to touch, soft and fluctuant, and was tender to palpate. He had a huge, firm, non- tender splenomegaly. He had sternal tenderness; and had no purpura, petechiae, ecchymosis, or other swelling on his body. Other system examinations including fundoscopy were normal.

On investigations: Haemoglobin - $5.2 \mathrm{~g} \%$, total WBC count $2,99,000 / \mathrm{mm}^{3}$ [differential count - Neutrophils-45, Lymphocytes-4, Eosinophils-3, Basophils-2, Blasts- 2, Promyelocytes-2, myelocytes- 18 , metacymyelocytes- 9 , band forms- 15]; n RBC/ 100WBC - 07/WBC; ESR- $125 \mathrm{~mm} / \mathrm{hr}$; Platelets- 232,000/ $\mathrm{mm}^{3}$. This blood smear was suggestive of CML in chronic phase. Liver and renal functions tests; PT, APTT, BT and CT were normal. Sr LDH was $1023 \mathrm{IU} / 1$ and $\mathrm{Sr}$ uric acid was $11.7 \mathrm{mg} \%$. Chest $\mathrm{x}$ ray showed homogenous opacity in the left mid and lower zones. Sonography of chest wall showed hypoechoic area within the muscles in the infra-

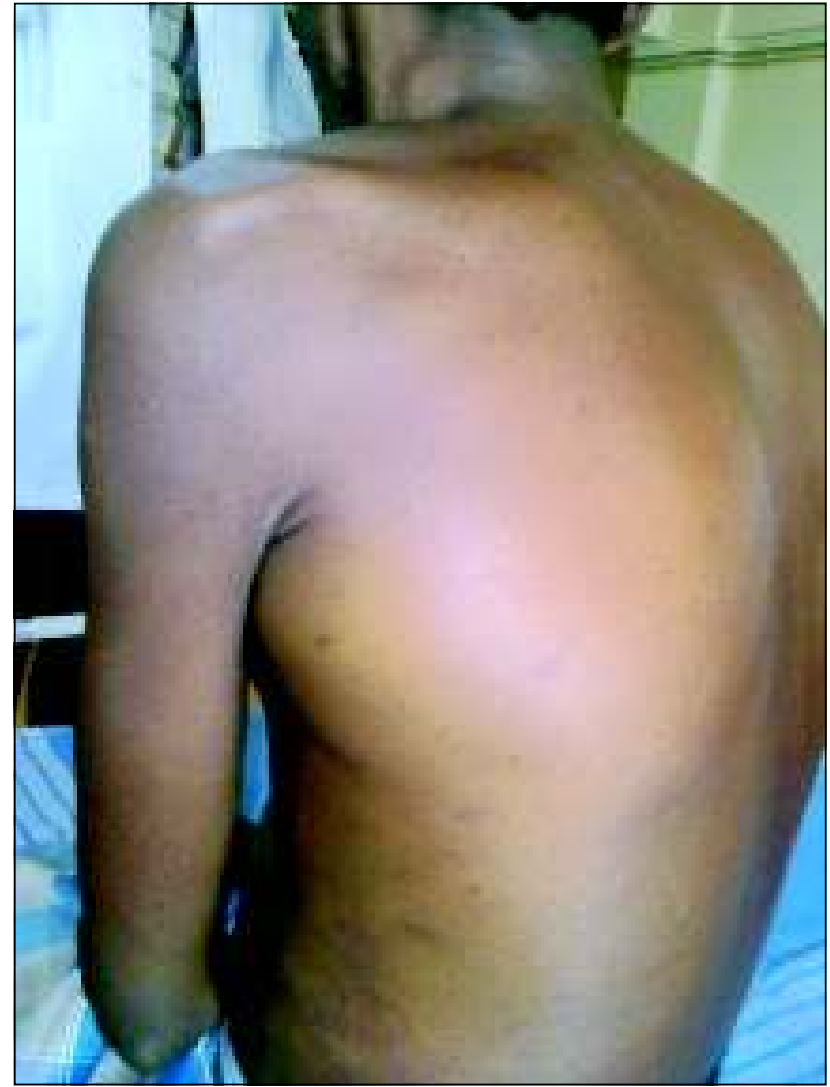

Fig.-1: Swelling in the left infra axillary area extending up to the scapula.

axillary area measuring 14x $6 \mathrm{~cm}$ (figure-2). Abdominal sonology showed an enlarged spleen and liver, measuring 18 and $3 \mathrm{~cm}$ below the costal margin respectively.

1. Associate Professor, Department of Medicine, Fr Muller Medical College, Fr Muller Road, Mangalore, S India.

2. Resident, Department of Medicine, Fr Muller Medical College, Fr Muller Road, Mangalore, S India.

3. Professor, Department of Medicine, Fr Muller Medical College, Fr Muller Road, Mangalore, S India. 575002

Correspondence : Dr Peter George MD, Associate Professor, Department of Medicine, Fr Muller Medical College, Fr Muller Road, Mangalore, S India. 575002; Phone: +91 9845177660,+91 824 2238000; Fax: +91 824 2436352; E mail: drpetergeorge2002@yahoo.com 

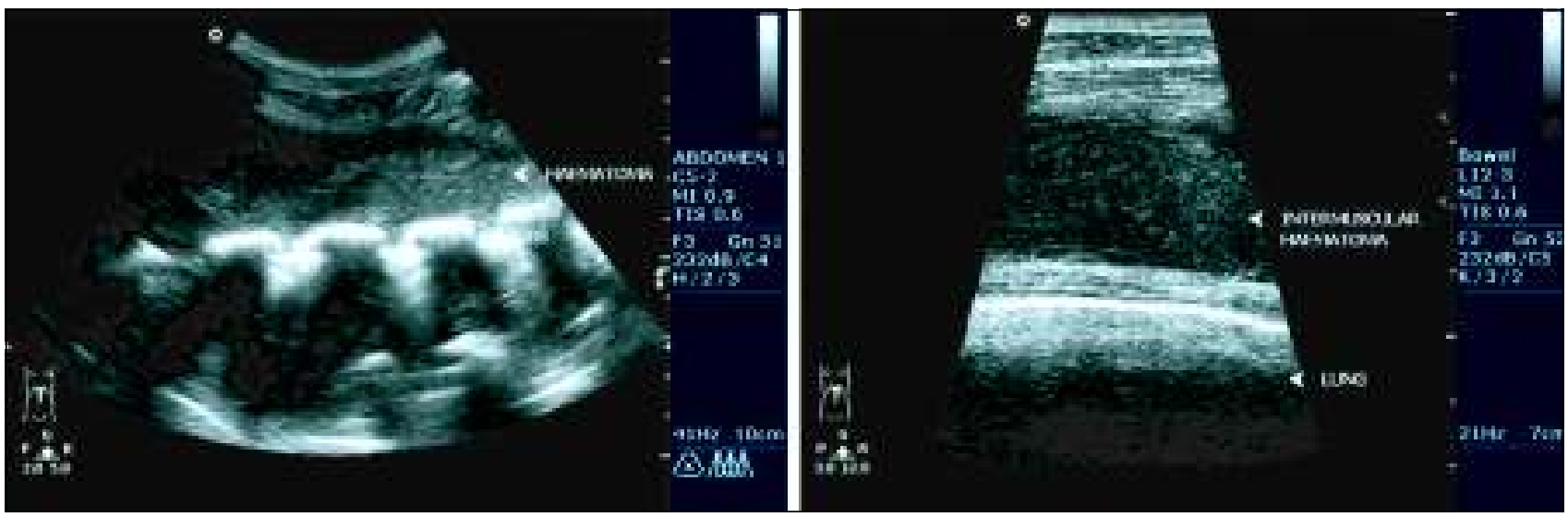

Fig.-2: Sonographic images showing intramuscular hematoma (marked and labelled) in relation to ribs and lung.

The bone marrow was hypercellular with erythroid: myeloid ratio of 6:1. Myeloid series were predominantly neutrophil and myelocytes. Erythroid series has normoblastic maturation, megakaryopoisis and lymphoplasmocytes were suppressed. The features were consistent with CML in chronic phase ${ }^{1}$.

The chromosomal study showed BCR-ABL gene positive $\mathrm{CML}^{1,5}$. The chest wall hematoma resolved without any complications over the next 2 weeks. Along with supportive therapy, he was started on hydroxurea for cytoreduction. Later he was started on imitinab and did not develop further spontaneous hematomas or bleeding; and doing well with regular follow-up.

\section{Discussion:}

Haematological, bleeding and clotting disorders rank high among the cause for spontaneous hematomas, followed by anti coagulant and anti platelet drugs. ${ }^{2,3}$ Spontaneous hematomas are increasingly encountered in practice, either idiopathic or due to coagulation and bleeding disorders, use of anti coagulant drugs, trauma, secondary malignancies. Spontaneous hematoma is rare and limited to sporadic case reports, associated with neoplasm, aneurysm and arteriovenous malformations. ${ }^{3}$ We are reporting the rare initial presentation of CML with spontaneous intra muscular chest wall hematoma.

Chronic myeloid leukemia is a hematopoietic clonal malignant disorder, with an acquired genetic defect in the pluripotential stem cell population. ${ }^{4} \mathrm{CML}$ has an incidence of 1 to 1.5 per 100,000 per year. The diagnosis is usually made in the relatively indolent chronic phase that remains stable for a number of years till a more aggressive phase. Majority of CML clinically present in the chronic phase of the disease, as seen with our case. In CML prior to its diagnosis, the patients are asymptomatic or they have nonspecific symptoms such as fatigue, fever, bone pain, or weight loss.

In the extensive review of literature, there are two reports of intra muscular hematomas occurring in CML. Kuo YC et al reported a case of CML who presented with mediastinal hematoma and hemothorax. Bauduceau $\mathrm{O}$ et al reported a case of spontaneous hematoma of the iliac psoas muscle in CML. ${ }^{6,7}$ There is no mention of any precipitating event prior to development of hematoma. In our case the patient had a trivial strain prior to the development of hematoma. There is a report of gluteal muscle hematoma in a case CML on chemotherapy for cytoreduction. ${ }^{8}$ There are few reports of spinal epidural hematomas as the initial presenting feature of CML. ${ }^{9}, 10$ Recently, Abdulhamid MM has reported a case of spontaneous acute subdural hematoma as the initial manifestation of chronic myeloid leukemia. ${ }^{11}$

The mechanism of spontaneous hematoma in CML is still debated. Specific platelet defects including abnormal platelet morphology, acquired storage pool disease, platelet membrane abnormalities, and abnormal arachidonic acid metabolism were thought to be the reason. ${ }^{2}$ It is believed that in CML the platelet dysfunction originated from a clonal expansion of dysfunctional megakaryocytes. These are possibly derived from the identical stem cell from which the CML blasts had originated. Thus the treatment targeting BCR-ABL would be equally effective in reducing the CML blasts and dysfunctional megakaryocytes. This is validated by observation that using tyrosine kinase inhibitors in patients with CML would improve the platelet dysfunction. ${ }^{5,8}$ Further research is required to understand, and would possibly improve the management of platelet dysfunction in CML. 


\section{Conclusion:}

Spontaneous bleeding is not rare with chronic myeloprliferative disorders, ane there are few reports on the same. To our knowledge, this is possibly the first report on CML presenting as spontaneous chest wall hematoma.

\section{Conflict of Interest: None}

\section{References:}

1. Goldman JM. Chronic myeloid leukemia: a historical perspective. Semin Hematol. 2010; 47: 302-11

2. Schafer AI. Bleeding and thrombosis in the myeloproliferative disorders. Blood. 1984; 64: 1-12

3. Wehmeier A, Daum I, Jamin H, Schneider W. Incidence and clinical risk factors for bleeding and thrombotic complications in myeloproliferative disorders. A retrospective analysis of 260 patients. Ann Hematol. 1991; 63: 101-6

4. Wehmeier A, Südhoff T, Meierkord F. Relation of platelet abnormalities to thrombosis and hemorrhage in chronic myeloproliferative disorders. Semin Thromb Hemost. 1997; 23: $391-402$

5. Schwarz J, Penka M, Campr V, Pospísilová D, Kren L, Nováková L, et al. Diagnosis and treatment of BCR/ABLnegative myeloproliferative diseases-principles and rationale of CZEMP recommendations.[Article in Czech] Vnitr Lek. 2011; 57: 189-213

6. Kuo YC, Wang HC, Chu KA, Lu JY. Chronic myeloid leukemia initially presenting with spontaneous mediastinal hematoma and hemothorax. Zhonghua Yi Xue Za Zhi (Taipei) $2000 ; 63: 170-4$

7. Bauduceau O, De Revel T, Fogelman J, Amadou S, Souleau B, Nedellec G. Spontaneous hematoma of the iliac psoas muscle in chronic myeloid leukemia. A case report. Ann Med Interne. 2003; 154: 183-6

8. Shimabukuro-Vornhagen A, Rothe A, Nogova L, Kochanek $\mathrm{M}$, Scheid C, von Bergwelt-Baildon M. Improvement of platelet dysfunction in chronic myelogenous leukemia following treatment with imatinib: a case report. J Med Case Reports. 2011; 5: 215

9. Banerjee R, Stanley J, Palumbo M. Spinal epidural hematoma induced by leukemia. Orthopedics. 2004; 27 : 864-6

10. Nojiri H, Kim S, Tsuji T, Uta S. Spontaneous spinal epidural hematoma as the initial presentation of leukemia. Eur Spine J. 2009; 18: 220-3

11. Abdulhamid MM, Li YM, Hall WA. Spontaneous acute subdural hematoma as the initial manifestation of chronic myeloid leukemia. J Neurooncol. 2011; 101: 513-6. 